\title{
Rehabilitation of discourse impairments after acquired brain injury
}

\author{
Gigiane Gindri ${ }^{1}$, Karina Carlesso Pagliarin¹, Fabíola Schwengber Casarin ${ }^{1}$, \\ Laura Damiani Branco ${ }^{1}$, Perrine Ferré2, Yves Joanette ${ }^{2}$, Rochele Paz Fonseca ${ }^{1}$
}

\begin{abstract}
Language impairments in patients with acquired brain injury can have a negative impact on social life as well as on other cognitive domains. Discourse impairments are among the most commonly reported communication deficits among patients with acquired brain damage. Despite advances in the development of diagnostic tools for detecting such impairments, few studies have investigated interventions to rehabilitate patients presenting with these conditions. Objective: The aim of this study was to present a systematic review of the methods used in the rehabilitation of discourse following acquired brain injury. Methods: The PubMed database was searched for articles using the following keywords: "rehabilitation", "neurological injury", "communication" and "discursive abilities". Results: A total of 162 abstracts were found, but only seven of these met criteria for inclusion in the review. Four studies involved samples of individuals with aphasia whereas three studies recruited samples of individuals with traumatic brain injury. Conclusion: All but one article found that patient performance improved following participation in a discourse rehabilitation program.
\end{abstract}

Key words: brain injuries, communication, language, rehabilitation.

\section{REABILITAÇÃO DE DIFICULDADES COMUNICATIVAS DISCURSIVAS PÓS-LESÃO CEREBRAL ADQUIRIDA}

RESUMO. Os prejuízos de linguagem observados em pacientes com lesões cerebrais adquiridas podem ocasionar impacto negativo na vida social do indivíduo assim como em outros domínios cognitivos. Prejuízos em habilidades discursivas estão entre os déficits comunicativos mais comumente reportados em pacientes com lesão cerebral adquirida. Apesar do avanço dos estudos sobre instrumentos para diagnosticar tais déficits, ainda são escassas as investigações que proponham um programa de intervenção para sequelas discursivas. Objetivo: Assim, esta revisão sistemática visou a caracterizar estudos de reabilitação do processamento comunicativo discursivo em casos pós-lesão cerebral adquirida. Métodos: Na base de dados PubMed utilizaram-se palavras-chave dos construtos "reabilitação", "lesão neurológica", "comunicação" e "habilidades discursivas". Resultados: Foram encontrados 162 abstracts, mas apenas sete apresentaram os critérios de inclusão para esta revisão. Quatro estudos envolveram amostras com indivíduos afásicos e três com indivíduos com traumatismo cranioencefálico. Conclusão: Todos, com exceção de um artigo, verificaram evolução dos pacientes após intervenção baseada no discurso.

Palavras-chave: traumatismos encefálicos, comunicação, linguagem, reabilitação.

\section{INTRODUCTION}

$\mathbb{1}_{\text {common consequences of acquired }}^{\text {otor and cognitive impairments are }}$ brain injury, and are often observed after strokes or traumatic brain injury (TBI). Such impairments may have a significant impact on the social functioning and quality of life of patients and their caregivers., ${ }^{1,2}$ Although many cognitive processes may be influenced by acquired brain injury, language complaints are among the most frequently reported by patients and their families. ${ }^{3}$ Language impairments may also have a negative influence on cognitive domains such as memory, attention and executive functions, as most of these processes are mediated by language. ${ }^{4,5}$

Both of the cerebral hemispheres play an important role in language processing. The left hemisphere (LH) is more closely associated with the formal components of language,

\footnotetext{
'Postgraduate Psychology Program - Department of Psychology - Pontifical Catholic University of Rio Grande do Sul, Porto Alegre, Rio Grande do Sul, Brazil. ¿Université de Montréal, Montréal, Canada.

Gigiane Gindri. Travessa Carmen, 75/205 - 90560-040 Porto Alegre RS - Brasil. E-mail: gigiane.gindri@gmail.com

Disclosure: The authors report no conflicts of interest.

Received November 10, 2013. Accepted in final form January 15, 2014.
} 
such as phonology, syntax, semantic and morphology. ${ }^{6-9}$ The right hemisphere (RH), on the other hand, is more heavily involved in pragmatic, lexical-semantic, prosodic and discursive processing. ${ }^{10-12}$

Although discourse processing deficits are an important cause of functional impairment, they have been scarcely studied in the literature. "Discourse" consists of using spoken or written language to convey ideas in an organized manner, and involves varying levels of language representation and semantic processing: ${ }^{13}$ Discourse relies on linguistic skills for grammatical processing, on pragmatic reasoning to understand the communicative intentions of other speakers and for inferential processing, and also recruits cognitive abilities such as attention, memory and executive functions. ${ }^{14}$ As a result, discourse is generally considered the most complex of communicative abilities. ${ }^{15}$ Van Djik notes that discourse is a way of representing the world through different levels and ${ }^{16}$ structures of language (words, phrases, sentences, speeches) in interaction with cognitive information processing.

Studies have shown that patients with acquired brain injury can have difficulty integrating the elements of a story into a coherent whole so as to comprehend it. These individuals may also have trouble taking listener needs into account ${ }^{12}$ and understanding the intentions of other speakers. ${ }^{17}$ Discourse production deficits have also been reported in the literature, the most common being impairments in storytelling, ${ }^{18}$ tangential speech, or difficulty staying on topic, ${ }^{19,20}$ and problems with conversational turn-taking. ${ }^{21,22}$

Some studies, such as the systematic review conducted by Ferré, Ska, Lajoie, Bleau and Joanette, ${ }^{23}$ have posited that both discourse production and comprehension require the involvement of both cerebral hemispheres. The LH recognizes words and engages in syntactic processing, while the $\mathrm{RH}$ is responsible for integrating information into a coherent whole. In addition, the $\mathrm{RH}$ is more heavily involved in locating and accessing less obvious semantic information. ${ }^{17}$

A number of authors have studied communication assessment in an effort to identify which instruments would be most sensitive and specific for clinical diagnoses and for the planning of therapeutic interventions. While most of these studies sought to investigate the role of both hemispheres, some have focused more specifically on the RH. ${ }^{24-27}$ Most discourse assessment batteries assess oral narrative ability through storytelling involving characters (spontaneous production) and investigate conversational discourse through the comprehension and production of dialogue between two or more speakers. ${ }^{28,29}$
Although research has been conducted into discourse impairments in individuals with brain injury (especially those with unilateral lesions), and assessment instruments are available to detect these conditions, very few studies have described methods for treating communicative deficits. Therefore, such methods have not been replicated and their effectiveness has not been assessed. Recent literature has demonstrated a growing interest in evidence-based rehabilitation and over the past few years some systematic reviews have attempted to establish guidelines for cognitive interventions. ${ }^{30-32}$ Reviews such as those by Ferré et al. ${ }^{23}$ and Tompkins ${ }^{33}$ have also sought to identify cognitive abilities that may have been neglected by rehabilitation research (see, for instance, $\left.{ }^{23,33}\right)$. These investigations have highlighted inconsistencies in studies of communication rehabilitation, especially those that target conversational discourse. ${ }^{34}$

In an attempt to assess the current state of research on communication impairments after acquired brain injury, the aim of the present study was to conduct a systematic review of the literature on discourse processing in individuals with such conditions.

\section{METHODS}

The PubMed database was searched in January of 2014 for articles investigating the following four constructs: "rehabilitation" AND "brain damage" AND "communication" AND "discourse abilities." Articles were retrieved using keywords that are frequently used in the literature on these topics. The keywords used for each construct topic were as follows: [a] Rehabilitation: "rehabilitation" OR "treatment" OR "functional recovery" OR "readaptation" OR "reeducation", "training" OR "intervention" OR "therapy" OR "remediation"; [b] Brain damage: "right hemisphere damage" OR "left hemisphere damage" OR "stroke" OR "lesion studies" OR "cerebrovascular disease" OR "cerebrovascular accident" OR "brain injury" OR "brain damage" OR "traumatic brain injury" OR "closed head injury"; [c] Communication: "linguistic" OR "language" OR "aphasia" OR "communication" OR "communicative"; [d] Discourse abilities: "discourse" OR "narrative" OR "conversation" OR "conversational" OR "dialogue". The electronic search was performed in two steps. Firstly, the sets of keywords referring to each of the four constructs were entered separately in the search box. Then, the results of all four searches were combined, and hand-filtered by the researchers. This review focused on articles published in English, French, Spanish or Portuguese.

All abstracts were independently screened by two reviewers, and articles were included in the review if they 
fulfilled the following criteria: [a] comprising an empirical study, [b] containing at least one adult with acquired brain injury in the sample, [c] focusing on discourse rehabilitation for patients with acquired brain injury, [d] providing a description of the intervention used, [e] involving non-pharmacological interventions.

When reviewers did not agree on article inclusion, a third rater read the article and made the final decision. The flow of articles through the systematic review process is illustrated in Figure 1.

\section{RESULTS}

Table 1 describes the studies included in the review. The characteristics of participants in the studies, the aim of each article, the pre- and post-intervention assessment method, and the results of each study are also given in the table.

\section{DISCUSSION}

A number of studies in the literature have tested language rehabilitation programs in individuals with acquired brain injury. ${ }^{35,36}$ However, these studies have focused mostly on therapy for anomia. The aim of the present study was to review the literature on discourse rehabilitation in adult patients with brain damage, although only seven studies met the initial inclusion criteria, as can be observed in Figure 1.

Most of the studies retrieved in the original search focused on language rehabilitation in patients with aphasia. This could be due to the fact that communication impairment following unilateral $\mathrm{LH}$ damage is a

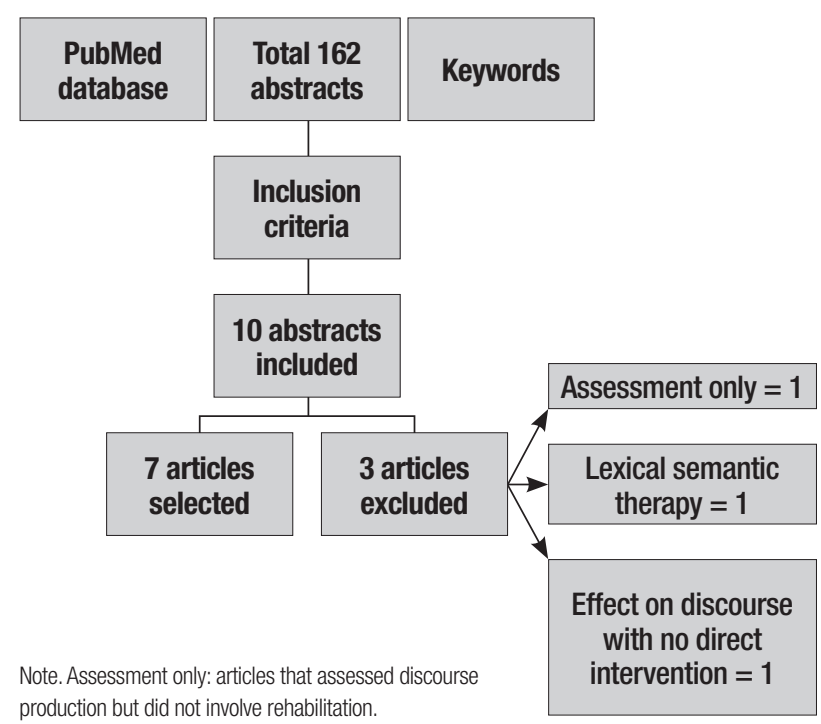

Figure 1. Flow of articles through the systematic review process. common cause of aphasia, which is, in turn, the most prevalent acquired language impairment. ${ }^{37}$ Therefore, the treatment of aphasia is a major goal of rehabilitation studies. ${ }^{35}$ However, even among these patients, discourse rehabilitation has been poorly investigated. ${ }^{31}$ Another possible cause of the lack of research on discourse rehabilitation following acquired brain injury is the fact that communication impairments following $\mathrm{RH}$ damage are underdiagnosed, and consequently, undertreated. ${ }^{38}$ The scarcity of research into discourse impairment among populations with bilateral or $\mathrm{RH}$ damage precludes the development of structured rehabilitation programs for patients with these conditions.

Three articles described rehabilitation programs aimed at individuals with TBI. These studies found that the cognitive impairment exhibited by these patients, who displayed attentional, mnemonic and executive alterations, led to difficulties in linguistic processing as well as discourse impairment. These findings underscore the need for further research into rehabilitation programs for patients with acquired brain injury. ${ }^{39,40}$

In spite of advances in communication assessment, few instruments have been developed to assess the different types of discourse, such as autobiographical and procedural. Even though studies show that such impairments may have a significant impact on the social functioning of individuals with brain damage, studies aimed specifically at discourse rehabilitation are still lacking, as are investigations of the efficacy of these interventions. ${ }^{23,33,41}$

Three of the studies included in the present review were conducted by the same group of researchers, ${ }^{42-44}$ who developed a software program for discourse rehabilitation. Their studies showed improvements in the communication skills of individuals with aphasia who completed the treatment program. Although the therapist was not an active participant in the rehabilitation process, patients contributed significantly to the development of the programs, so as to ensure that their needs were addressed. ${ }^{43}$ The use of a computer appeared to make rehabilitation more accessible to the patients, who were able to complete the activities in their own home. These methods have the added advantage of allowing participants to engage in rehabilitation activities multiple times a week. ${ }^{30}$ However, there may be some drawbacks of exclusive use of software for language rehabilitation, such as the fact that human interaction, which favors the development of communication skills, is absent from the treatment. Simmons-Mackie, Elman, Holland and Damico ${ }^{45}$ have suggested that the benefits of group therapy may stem from the fact that it favors 


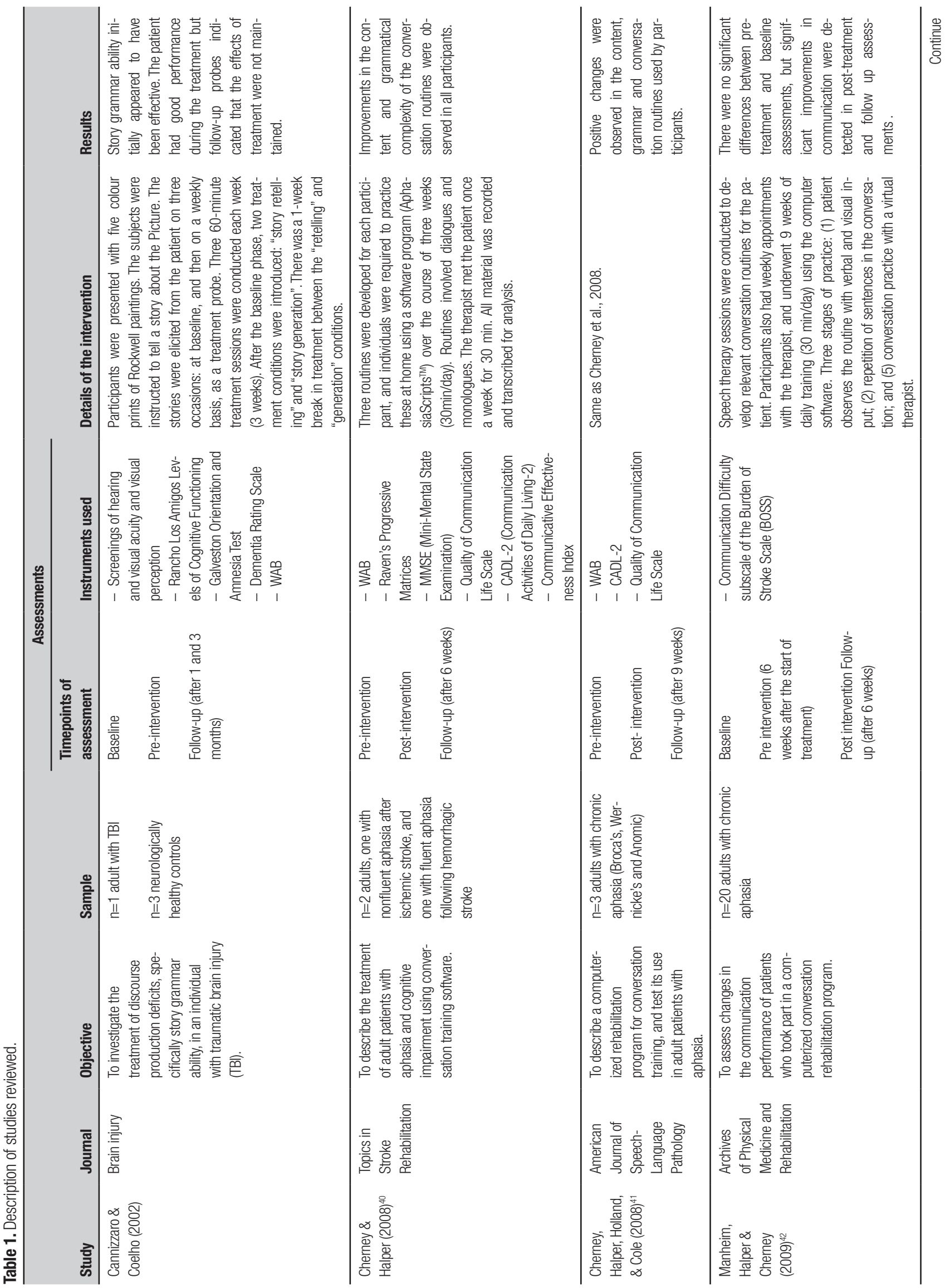




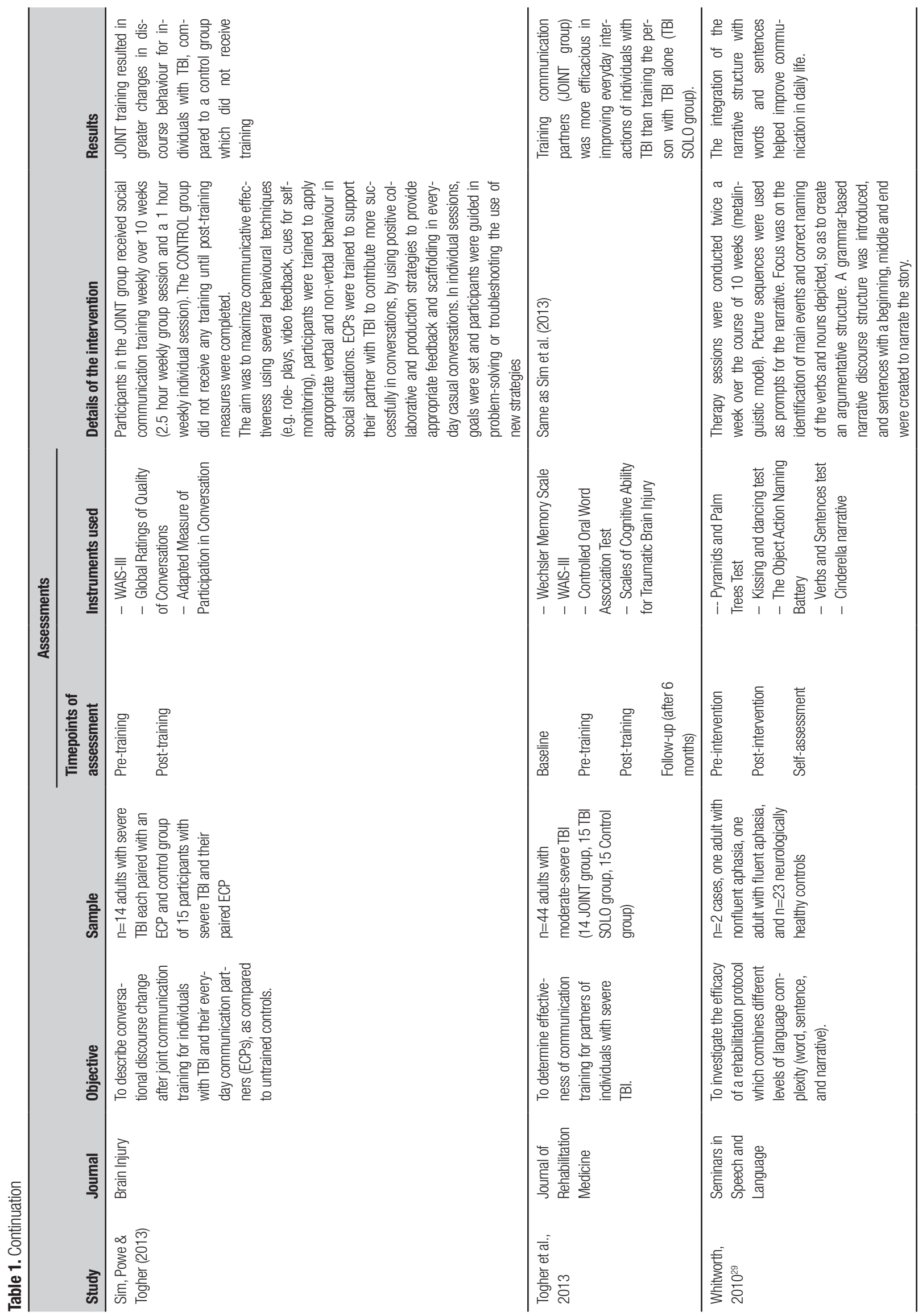


the formation of communication dyads, which simulate real social interactions.

Social isolation and restriction in social interactions after stroke may have a negative impact on quality of life. Similarly, the inability to work may lead to lower quality of life, especially in individuals younger than 65 years, as employment has been shown to have an influence on self-concept, social status and social relationships ${ }^{46}$. Therefore, problems of social identity may be one of the factors responsible for worse subjective and psychological well-being following stroke. Other factors that may contribute to this situation are functional incapacity, cognitive deficits and depression. The low social support associated with reduced social interaction could also increase feelings of loneliness and hopelessness, and may have an impact on the efficacy of therapeutic interventions. ${ }^{47}$

The articles included in the present review assessed participant performance at baseline, immediately before and after treatment, and at follow up. Participants were evaluated using ecological assessments scales, ${ }^{42-44}$ language assessment batteries ${ }^{29,42,43}$ and story-telling. ${ }^{29}$

Although pre- and post-assessment measures are important, they may not be able to indicate whether specific discourse skills were acquired as a result of rehabilitation, or determine how long the treatment should continue. It may have also been useful to assess participants during the intervention period, so as to monitor patients' progress over the course of treatment. The variability in assessment methods across the studies reviewed also prevented comparisons between their results. ${ }^{23,33}$

It is important that studies of communication rehabilitation provide detailed descriptions of their interventions so that their methods can be replicated. $.^{34} \mathrm{Fac}-$ tors including variability in study design, small sample sizes, and the omission of methodological descriptions make it difficult to replicate these studies and to compare their results, preventing the generalization of findings to other populations.

Some authors have claimed that the existing literature is sufficient to provide a solid basis for the development of rehabilitation programs for patients with aphasia. ${ }^{30,31}$ However, there is no consensus as to the efficacy of these procedures. ${ }^{48}$ Three of the seven studies included in the present review had no control group and based their results on two or more cases. These studies can only provide class III evidence for the efficacy of the rehabilitation programs used. The study conducted by Whitworth ${ }^{29}$ was able to provide class II evidence, as it assessed the efficacy of an intervention in two clinical cases and involved the use of a control group. ${ }^{30}$ Studies that provide class II and III evidence may be useful in proving the efficacy of rehabilitation programs, defined as the probability an individual from a particular clinical population will benefit from the intervention. ${ }^{49,50}$

The current literature provides recommendations for interventions aimed at improving discourse impairments, as well as guidelines on how to reduce impairments and improve communication through realistic communication activities, especially those that involve social interaction. ${ }^{23}$ Although recommendations based on clinical practice may lack the methodological rigor of randomized controlled trials, or class I evidence, these methods have produced positive results in the past. ${ }^{30,51}$ However, studies of the effectiveness of language rehabilitation programs are insufficient to draw firm conclusions, and there is a clear need for scientifically based evidence, and for clinical trials similar to those conducted for medications and transcranial magnetic stimulation in patients with aphasia. One of the most important methodological limitations of the studies analyzed is the variability in the treatment methods used. Although in clinical practice methods must be adapted to each particular case, these variations make it difficult to identify the strengths and weaknesses of each respective method. ${ }^{52}$

Thus, there is a need for further research into the benefits that patients with acquired brain damage may expect to obtain from discourse-based treatments. It is also necessary to determine which methods should be used and what objectives should be pursued in rehabilitation studies, as well as what instruments should be used to assess participant performance. In conclusion, the development of rehabilitation programs for patients with discourse impairments could make significant contributions to clinical practice in speech therapy and neuropsychology. ${ }^{51}$ It is necessary to seek a consensus regarding general aspects of discourse rehabilitation, and to determine which instruments should be used to search for evidence of the efficacy of such interventions in improving sociocommunicative interactions and quality of life in patients with acquired brain injury and in their relatives.

The present findings should be interpreted in light of a few limitations. The keywords used in the electronic search retrieved a relatively small number of articles, which may impair the generalizability of the present results. The variability in the presentation of discourse alterations following acquired brain lesions may also impair the generalization of findings across samples. Consequently, the results of the articles discussed in the 
present review should be interpreted exclusively in the context of the populations studied. Nevertheless, the present review was able to identify the need for further research into discourse rehabilitation in populations with acquired brain injury, as well as for a greater number of publications in the area. It is suggested that similar reviews be conducted based on articles retrieved from other electronic databases, using different sets of search words. Additionally, the effectiveness of other interventions, such as rehabilitation programs aimed at the caregivers or relatives of patients with discourse impairments associated with neurological conditions, should also be investigated.

Acknowledgements. The authors would like to thank the Coordination for the Improvement of Higher Level Personnel (CAPES) for the doctoral grants awarded to Gigiane Gindri and Fabíola Schwengber Casarin, and the National Council for Scientific and Technological Development (CNPq) for the doctoral grant awarded to Karina Carlesso Pagliarin. This research was conducted as part of the doctoral thesis of the first author.

\section{REFERENCES}

1. Brookshire $\mathrm{RH}$. Introduction to neurogenic communication disorders. ERIC; 1997.

2. Jørgensen HS, Nakayama H, Raaschou HO, Olsen TS. Recovery of walking function in stroke patients: the Copenhagen Stroke Study. Arch Physic Med Rehab 1995;76:27-32.

3. Murray L, Coppens P. Formal and informal assessment of aphasia. In: Papathanasiou I, Coppens P, Potagas C, editors. Aphasia and related neurogenic communication disorders. Burlington: Jones \& Bartlett Learning; 2012.

4. Mourik $M$ van, Verschaeve $M$, Boon P, Paquier P, Harskamp F van. Cognition in global aphasia: Indicators for therapy. Aphasiology 1992;6: 491-499.

5. Zaidel E, Kasher A, Soroker N, Batori G. Effects of right and left hemisphere damage on performance of the "Right Hemisphere Communication Battery". Brain lang 2002;80:510-535.

6. Herrmann M, Koch U, Johannsen-Horbach H, Wallesch CW. Communicative skills in chronic and severe nonfluent aphasia. Brain Lang 1989; 37:339-352.

7. Ortiz KZ, Ferreira CP, Bento ACP. Aplicação do teste Beta 86 (protocolo Mt modificado) em analfabetos. Fono atual 2006;8:65-73.

8. Pedersen PM, Vinter K, Olsen TS. Aphasia after stroke: type, severity and prognosis. The Copenhagen aphasia study. Cerebrovasc Dis 2004; 17:35-43.

9. Rousseaux M, Daveluy W, Kozlowski O. Communication in conversation in stroke patients. J Neurol 2010;257:1099-1107.

10. Blake ML. Inferencing processes after right hemisphere brain damage: effects of contextual bias. J Speech Lang Hear Res 2009;52: 373-384.

11. Cote H, Payer M, Giroux F, Joanette Y. Towards a description of clinical communication impairment profiles following right-hemisphere damage. Aphasiology 2007;21:739-749.

12. Myers PS. Right hemisphere damage: Disorders of communication and cognition. Singular Pub.; 1999.

13. Harley TA. The psychology of language: From data to theory. Taylor \& Francis; 2001.

14. Brandão L. Discurso e cognição em suas variantes da demência frontotemporal e na doença de Alzheimer. Rev Neuropsicol Latinoam 2010; 2:11-24.

15. Robertson DA, Gernsbacher MA, Guidotti SJ, et al. Functional neuroanatomy of the cognitive process of mapping during discourse comprehension. Psychol Sci 2000;11:255-260.

16. Van Djik TA. Context and language. Discourse and context: a sociocognitive approach. New York: Cambridge University Press; 2008.

17. Tompkins CA, Scharp VL, Fassbinder W, Meigh KM, Armstrong EM. A different story on "theory of mind" deficit in adults with right hemisphere brain damage. Aphasiology 2008;22:42-61.

18. Lehman Blake M. Clinical relevance of discourse characteristics after right hemisphere brain damage. Am J Speech Lang Pathol 2006; 15:255-267.

19. Barnes S, Armstrong E. Conversation after right hemisphere brain damage: motivations for applying conversation analysis. Clin Ling Phon 2010;24:55-69.

20. Jorgensen M, Togher L. Narrative after traumatic brain injury: a com- parison of monologic and jointly-produced discourse. Brain Inj 2009;23: 727-740.

21. Hird K, Kirsner K. The effect of right cerebral hemisphere damage on collaborative planning in conversation: an analysis of intentional structure. Clin Ling Phon 2003;17:309-315.

22. Angeleri R, Bosco FM, Zettin M, Sacco K, Colle L, Bara BG. Communicative impairment in traumatic brain injury: a complete pragmatic assessment. Brain Lang 2008:229-245.

23. Ferré P, Ska B, Lajoie C, Bleau A, Joanette Y. Clinical Focus on Prosodic, Discursive and Pragmatic Treatment for Right Hemisphere Damaged Adults: What's Right? Rehab Res Prac 2011;2011:1318-1320.

24. Bryan K. The right hemisphere language battery. Far Communications England; 1989.

25. Joanette $\mathrm{Y}$, Ska B, Cote $\mathrm{H}$. Protocole $\{\mathrm{MEC}\}$, Protocole Montréal d'évaluation de la communication. Ortho Éd.; 2004.

26. Pimental PA, Kingsbury NA. Mini Inventory of Right Brain Injury. Texas: Pro-Ed.; 1989.

27. Ross-Swain D. Ross information processing assessment. Pro-Ed.; 1986.

28. Ribeiro AF. A utilização de inferências visuais na elaboração do discurso oral de indivíduos normais e indivíduos com lesão de hemisfério direito (Tese). Universidade de São Paulo; 2011.

29. Whitworth A. Using narrative as a bridge: linking language processing models with real-life communication. Semin Speech Lang 2010;31: 64-75.

30. Cicerone KD, Dahlberg C, Kalmar K, et al. Evidence-based cognitive rehabilitation: recommendations for clinical practice. Archives of Physical Medicine and Rehabilitation. WB SAUNDERS CO; 2000;81: 1596-1615.

31. Cicerone KD, Dahlberg C, Malec JF, et al. Evidence-based cognitive rehabilitation: updated review of the literature from 1998 through 2002. Arch Phys Med Rehabil 2005;86:1681-1692.

32. Cicerone KD, Langenbahn DM, Braden C, et al. Evidence-based cognitive rehabilitation: updated review of the literature from 2003 through 2008. Arch Phys Med Rehabil 2011;91:519-530.

33. Tompkins CA. Rehabilitation for cognitive-communication disorders in right hemisphere brain damage. Arch Phys Med Rehabil 2012;93: 61-69.

34. Rispoli MJ, Machalicek W, Lang R. Communication interventions for individuals with acquired brain injury. Dev Neurorehabil 2010;13:141-151.

35. Ardila A. A proposed reinterpretation and reclassification of aphasic syndromes. Aphasiology 2010;24:363-394.

36. Maher LM, Raymer AM. Management of anomia. Top Stroke Rehabil 2004;11:10-21.

37. Foerch C, Misselwitz B, Sitzer M, Berger K, Steinmetz H, NeumannHaefelin T. Difference in recognition of right and left hemispheric stroke. Lancet 2005;366:392-393.

38. Morris J. Effects of right hemisphere strokes on personality functioning. Top Stroke Rehabil 2009;16:425-430.

39. Sim P, Power E, Togher L. Describing conversations between individuals with traumatic brain injury (TBI) and communication partners following communication partner training: Using exchange structure analysis. Brain Inj 2013;27:717-742. 
40. Togher L, McDonald S, Tate R, et al. Training communication partners of people with severe traumatic brain injury improves everyday conversations: a multicenter single blind clinical trial. J Rehabil Med 2013;45: 637-645.

41. Stuss DT, Winocur G, Robertson $\Vdash$ H. Cognitive Neurorehabilitation: Evidence and Application. New York: Cambridge University Press; 2008.

42. Cherney LR, Halper AS. Novel technology for treating individuals with aphasia and concomitant cognitive deficits. Top Stroke Rehabil 2008: 542-554.

43. Cherney LR, Halper AS, Holland AL, Cole R. Computerized script training for aphasia: preliminary results. Am J Speech Lang Pathol 2008; 17:19-34.

44. Manheim LM, Halper AS, Cherney L. Patient-reported changes in communication after computer-based script training for aphasia. Arch Physic Med Rehabil 2009;90:623-627.

45. Simmons-mackie N, Elman RJ, Holland AL, Damico JS. Management of Discourse in Group Therapy for Aphasia. Top Lang Disord 2007; 70420:5-23.

46. Carod-Artal J, Egido JA, González JL, Varela De Seijas E. Quality of life among stroke survivors evaluated 1 year after stroke: experience of a stroke unit. Stroke 2000;31:2995-3000.
47. Rabelo DF, Neri AL. Recursos psicológicos e ajustamento pessoal frente à incapacidade funcional na velhice. Psicol Est 2005;10:403412.

48. Cappa SF, Benke T, Clarke S, Rossi B, Stemmer B, Van Heugten CM EFNS guidelines on cognitive rehabilitation: report of an EFNS task force. Eur J Neurol 2003;10:665-680.

49. Rodriguez AD, Rothi LJG. Principles in conducting rehabilitation research. In: Stuss DT, Winocur G, Robertson $\Vdash$, editors. Cognitive Neurorehabilitation: evidence and application. 2nd ed. New York: Cambridge University Press; 2008:79-90.

50. Wilson B. Evidence for the effectiveness of neuropsychological rehabilitation. In: Wilson B, Gracey F, Evans JJ, Bateman A, editors. Neuropsychological rehabilitation: theory, models, therapy and outcome. New York: Cambridge University Press; 2009:22-36.

51. Mackenzie C, Brady M. Communication difficulties following right hemisphere stroke: applying evidence to clinical management. Evid Based Commun Asses Interv 2008;2:235-247.

52. De Noreña D, Ríos-Lago M, Bombín-González I, Sánchez-Cubillo I, García-Molina A, Tirapu-Ustárroz J. Efectividad de la rehabilitación neuropsicológica en el daño cerebral adquirido (I): atención, velocidad de procesamiento, memoria y lenguaje. Rev Neurol 2010;51:687-698. 